\title{
Dog Bites among Off-Road Cyclists: A Report of Two Cases
}

\author{
Majid Ansari ${ }^{1}$, MD; Masih Shafiei ${ }^{1}$; Ramin Kordi*1 ${ }^{1}$, MD
}

Authors' Affiliation:

Sports Medicine Research Center, Tehran University of Medical Sciences, Tehran, Iran

* Corresponding Author;

Address: Sports Medicine Research

E-mail: ramin_kordi@tums.ac.ir

Received: Oct 29, 2011

Accepted: Dec 29, 2011

Key Words: Dog; Bites;

Management; Off-Road Cycling;

Recommendation

\begin{abstract}
Background: As the field of off-road cycling is usually remote areas with limited access to medical care, off-road cyclists are at higher risk of animal attacks and related injuries.

Case presentation: We report two cases of dog attacks in off-road cycling and discuss the basic principles in prevention and management of such incidents. The cyclists received all 5-dose regimen of the rabies vaccine and returned to sport after 6 weeks. During 6-month follow-up period, no complications were observed.

Conclusions: To reduce the probability of dog attacks and its complications, the off-road cyclists should be familiar with some basic principles. They should also be educated about initial on-site management of the related injuries, which may have a great impact on decreasing further complications.
\end{abstract}

Asian Journal of Sports Medicine, Volume 3 (Number 1), Mar 2012, Pages: 60-63

\section{INTRODUCTION}

The popularity of off-road cycling (mountain biking) is growing in different communities ${ }^{[1]}$. Off-road cyclists are in higher risk of animal attacks, since the field of this sport is usually off-road tracks far from urban areas. Off-road cyclists could be at higher risk of local and systemic complications following animal bites due to lack of immediate access to medical care in the remote areas.

Dog bites can inflict a large amount of pressure on tissues leading to crush injuries possibly accompanied by lacerations, puncture wounds, and similar soft tissue injuries ${ }^{[2]}$. Wound infection, especially with rabies, is of major concern in endemic areas.

Based on our knowledge, there has been no previously published article regarding initial managements of bite wounds among off-road cyclists. Here, we present two cases of dog bites in mountain cyclists. Then some of the circumstances surrounding the occurrence and management of dog bite related injuries among off-road cyclists will be discussed.

\section{CASE PRESENTATION}

\section{Case 1:}

A 25 year-old male professional off-road cyclist accompanying a group of twelve recreational mountain cyclists were cycling on a 25-kilometer upslope dirt road. He was riding about 5 minutes ahead of the rest of the group when he was attacked by two shepherd dogs and bitten on the left knee. He was using earphones to listen to music, so he did not notice the dog barks right before the attack.

At the site of event, the victims' wound was washed with drinking water and dressed at the site of event by the cyclists' recreational coach. Then the injured cyclist was transferred to the nearest medical center by the group's support vehicle.

On admission, physical examinations revealed several puncture wounds on the left knee, with the size ranging from 5 to $10 \mathrm{~mm}$. On examination, no neurovascular or wound infection signs were detected. The physical examination was otherwise normal. Initial wound management was carried out. Rabies post- 
exposure prophylaxis (PEP) was required following the national guidelines, so the patient received Purified Vero cell rabies vaccine (PVRV) and human rabies immunoglobulin (HRIG, $20 \mathrm{IU} / \mathrm{Kg}$ ). Prophylactic doxycycline (100 mg, twice daily) and clindamycin (450 mg, three times daily) was administrated for 7 days, due to the prior allergy of the patient to penicillin. Based on past history of completed tetanus immunization (with the last dose of tetanus vaccine administrated less than 5 years ago), tetanus prophylaxis was not required. The cyclist received all the rabies vaccine doses according to the 5-dose regimen guideline (on days $0,3,7$ and 14) but the last dose (on day 28). The cyclist returned to sport after 14 days. During 6-month follow up, no complications were reported.

\section{Case 2:}

A 22 year-old male recreational off-road cyclist was cycling on a 35 kilometer off-road dirt track with a group of peers. He was hindered from the rest of the group to fix a flat tire. He was attacked by a shepherd sheep dog, while he was catching up with the rest of the group. First he turned his bicycle around to run away from the attacking dog, but the dog caught up with him and he was bit on the left ankle and calf.

Right after the event, the victim's wounds were washed with a relatively little amount of water (750 milliliters), since the group was approaching the end of the course and most of their water was already consumed. The wound was dressed using a small first aid kit carried by one of the cyclists. Since the group had no support vehicle, the victim was carried to the nearest medical center by an Environment Protection's vehicle that was passing by, while patrolling the area.

On physical examination, several puncture wounds and lacerations ranging from 3 to $15 \mathrm{~mm}$ in diameter, on the left ankle and calf were noted. Neither neurovascular nor wound infection signs were detected. The examination was otherwise normal. After initial wound management, rabies post-exposure prophylaxis, including PVRV and HRIG (20 IU/Kg) was administrated. The patient received antibiotic prophylaxis with oral amoxicillin-clavulanate (675/125 $\mathrm{mg}$, twice daily). Tetanus prophylaxis was not required due to the patient's history of complete tetanus vaccination (less than 5 years ago). The 5-dose regimen of PEP rabies vaccine was completed. The cyclist returned to sport after 6 weeks. Through the 6-month follow-up period, no complications were observed.

\section{DISCUSSION}

From a primary prevention point of view, dogs tend to be more aggressive and violent when encountering a solitary cyclist, rather than a group of cyclists. In both cases presented above, victims were attacked by dogs while they had been separated from their groups. Thus, forming a homogeneous group of cyclists and asking the cyclists to stay in group may help reduce the probability of dog attacks. No cyclist should be left behind when he/she has to stop. To avoid unaccompanied cycling in such remote areas seems to be logical as well.

In the first case, the victim did not hear the dogs barking because of the earphones. Had he become aware of the threat, he could possibly avoid the situation. Thus it is also recommended to avoid using devices that can limit the awareness of the cyclist from his environment.

Of interest is the fact that the second cyclist tried to run away from the dog. Dogs tend to chase moving objects. In standing position, it is recommended to stand still, put the legs together, and fold the arms against the body to protect the face and neck while the elbows are placed in front of the chest. If you are knocked to the ground by the dog, try to stand still while laying face down, put the legs together and protect the neck and head by hands ${ }^{[3]}$.

Dog bite wounds (with the exception of puncture wounds) should be washed by copious amounts of water using pressure irrigation (Fig. 1). Wound irrigation plays a role in prevention of wound infection, especially in the cases of a suspected rabid dog. Minimizing the weight of the mountain bike and its related equipments is exceedingly becoming an issue of interest among off-road cyclists. It may even extend to limiting the amount of water and the first aid equipments carried. On the other hand, water is 


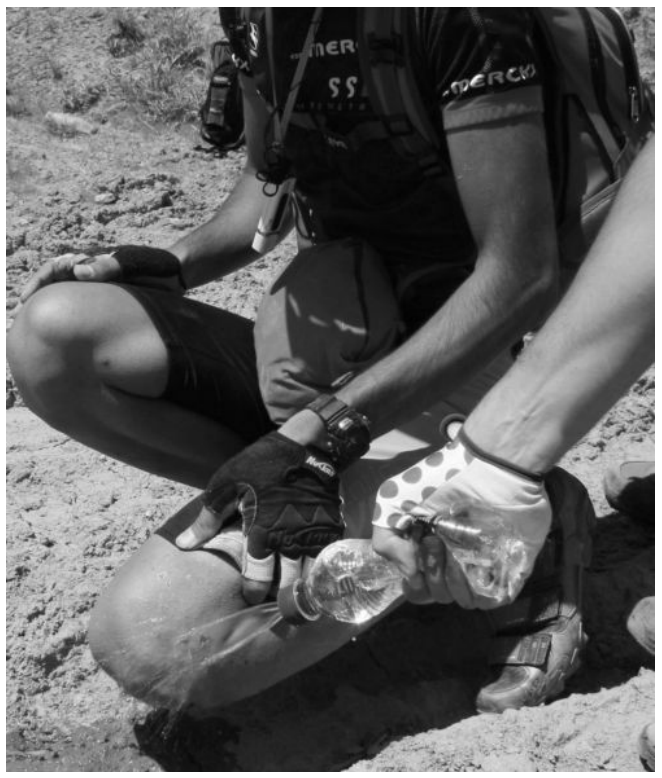

Fig. 1: Pressure irrigation using primary equipments available in off-road cyclist's bag

gradually drunk by the cyclists during the course. Thereby the needed amount of water may not be available at the time of incident. So, the amount of water to be carried by each cyclist should be increased. It also seems rational to have a support vehicle in the immediate access by the cyclists to provide any necessary assistance.

In the first case, the victim did not receive the last dose of the 5-dose regimen of PEP rabies vaccine. According to the national guidelines for rabies PEP which is compatible with the World Health Organization (WHO) guideline, under some conditions a 4-dose regimen of PEP vaccine can be used as an alternative to the 5 -dose regimen ${ }^{[5]}$. The 4-dose vaccine regimen should be administered at days $0,3,7$ and 14. CDC also recommends a 4-dose regimen of rabies vaccine ${ }^{[6]}$. Therefore, it seems that injection of the fifth dose of the vaccine should be left upon the decision of the physician.

In summary, to decrease the probability of dog attacks in off-road cyclists, we propose a few recommendations (Table 1). The off-road cyclists should also be well-informed about the initial management of dog bite related injuries (Table 2).

The athletes have to know that the initial wound management must be applied at the site of event and the victim should be immediately transferred to the nearest medical center for further evaluation and management of the wound.

Table 1: Recommendations for prevention and management of dog attacks and related injuries

\begin{tabular}{|c|c|}
\hline Decreasing the probability of dog attacks & $\begin{array}{l}\text { Necessary preparations for the management of dog } \\
\text { bite }\end{array}$ \\
\hline $\begin{array}{l}\text { Form a homogeneous group of cyclists, stay in group, not to } \\
\text { leave a cyclist behind }\end{array}$ & Carry enough amount of water \\
\hline To avoid unaccompanied cycling in remote areas & Do not forget to pack the first aid kit \\
\hline Do not run away from a dog ${ }^{[4]}$ & A support vehicle should be in immediate access \\
\hline $\begin{array}{l}\text { Avoid using equipments that limit your awareness of the } \\
\text { surroundings (e.g. listening to loud music using earphones) }\end{array}$ & $\begin{array}{l}\text { Learn the Initial wound management and bite wound } \\
\text { management (Table 2) }\end{array}$ \\
\hline
\end{tabular}


Table 2: Step by step initial management of dog bite wounds ${ }^{[7,8]}$

\begin{tabular}{|c|c|c|}
\hline St & & Action \\
\hline 1 & Stabilization & $\begin{array}{l}\text { Direct pressure for actively bleeding wounds } \\
\text { Neurological examinations of distal areas to the wound }{ }^{\text {a }}\end{array}$ \\
\hline 2 & Wound preparation ${ }^{b}$ & $\begin{array}{l}\text { Cleaning the surface of the wound (using soap and water }{ }^{c} \text { or water }{ }^{c} \text { alone for } 15 \\
\text { minutes or } 1 \% \text { povidone iodine or } 1 \% \text { benzalkonium chloride) } \\
\text { In-depth irrigation (with water }{ }^{c} \text { using pressure irrigation) } \\
\text { Debridement of devitalized tissue } \\
\text { Dressing the wound }\end{array}$ \\
\hline
\end{tabular}

\section{CONCLUSION}

Here we discussed some of the circumstances surrounding the occurrence and management of dog bites in off-road cyclists. To reduce the probability of dog attacks and its complications, they should know some basic principles discussed earlier. In this regard, they should be educated about initial on-site management of dog bite related injuries, which is easy to learn and may have a great impact on decreasing further complications.

\section{Acknowledgement}

The authors would like to thank Mr. Mohsen Mohammadi for providing the photograph.

\section{REFERENCES}

1. Jeys LM, Cribb G, Toms AD, Hay SM. Mountain biking injuries in rural England. Br J Sports Med 2001;35:197-9.

2. Abrahamian FM. Dog bites: bacteriology, management, and prevention. Curr Infect Dis Rep 2000;2:446-53.

3. Presutti RJ. Prevention and treatment of dog bites. Am Fam Physician 2001;63:1567-72.

4. $\quad$ Sacks JJ, Lockwood R, Hornreicht J, Sattin RW. Fatal Dog Attacks, 1989-1994. Pediatrics 1996;97:891-5.

5. Human and dog rabies prevention and control: report of theWHO/Bill \&Melinda Gates Foundation consultation, Annecy, France, 7-9 October 2009. Geneva: World Health Organization (WHO/HTM/NTD/NZD/2010.1). Available at: http://whqlibdoc.who.int/hq/2010/ WHO_HTM_NTD_NZD_2010.1_eng.pdf. Access date: Dec. 10, 2011

6. Rupprecht CE, Briggs D, Brown CM, et al. Use of a Reduced (4-Dose) Vaccine Schedule for Postexposure Prophylaxis to Prevent Human Rabies [CDC web site]. March 10, 2010. Available at: http://www.cdc.gov/mmwr/preview/mmwrhtml/rr5902a1.htm. Access date: Jan 22, 2011.

7. Local treatment of wounds [WHO web site]. Available at: http://www.who.int/rabies/vaccines/treatment_wound/en. Access date: Jan 10, 2011.

8. Endom EE. Initial management of animal and human bites. 2010. Available at: www.uptodate.com . Access date: Jan 13, 2011.

9. Morgan M, Palmer J. Dog bites. Br Med J 2007;334:413-7. 